\title{
Dynamic Pupillometry in Type 2 Diabetes: Pupillary Autonomic Dysfunction and the Severity of Diabetic Retinopathy
}

This article was published in the following Dove Press journal: Clinical Ophthalmology

\author{
Samyukta Bista Karki ${ }^{1}$ \\ Kirsten J Coppell $\mathbb{D D}^{2}$ \\ Logan V Mitchell ${ }^{2}$ \\ Kelechi C Ogbuehi $\mathbb{D}^{2}$ \\ 'Drishti Eye Care Center, Kathmandu \\ 44600, Nepal; ${ }^{2}$ Department of Medicine, \\ Dunedin School of Medicine, University \\ of Otago, Dunedin 9054, New Zealand
}

Correspondence: Kelechi C Ogbuehi Department of Medicine, Dunedin School of Medicine, University of Otago, 20I Great King Street, Dunedin 9054, New Zealand

Tel +6434740999 Ext 58308

Email kelechi.ogbuehi@otago.ac.nz
Purpose: Autonomic dysfunction may precede the microvascular changes that characterise diabetic retinopathy. The aim of this pilot study was to measure and compare pupillometry indices in type 2 diabetes (T2DM) patients - with and without diabetic retinopathy - and in healthy, age-matched controls.

Methods: Two hundred and eleven participants with T2DM aged 45-80 years were recruited from Dunedin Hospital Eye Department, Dunedin, New Zealand. They were categorised into three groups - no, mild/moderate, or severe diabetic retinopathy. Seventy age-matched, diabetes screen negative control participants were recruited from the Dunedin city community. Dynamic pupillometry was performed using an infrared pupillometer. The main outcome measures were maximum constriction velocity, average constriction velocity, absolute constriction amplitude, relative reflex amplitude, average dilation velocity and 75\% re-dilation (recovery) time. Outcome measures were compared between study groups using the Kruskal-Wallis nonparametric test (with Dunn's multiple comparison post-test).

Results: Pupillary parasympathetic function differed between groups. Maximum constriction velocity $(\mathrm{p}<0.001)$ and average constriction velocity $(\mathrm{p}<0.001)$ were slower, and absolute constriction amplitude $(\mathrm{p}<0.001)$ and relative reflex amplitude $(\mathrm{p}<0.05)$ were lower in the three diabetes groups compared with controls. There were no significant differences in pupillary sympathetic function between the four groups for re-dilation time, but the diabetes groups had significantly slower average dilation velocity times.

Conclusion: Pupillary light reflex is significantly impaired with diabetic retinal neuropathy, before clinically observable signs of diabetic retinopathy. Dynamic pupillometry may be a cheap, clinically relevant test, but sensitivity and specificity need to be determined before utilising as a screening tool for diabetic retinopathy.

Keywords: diabetic autonomic neuropathy, diabetic retinopathy, diabetic macular oedema, pupillary reflex, parasympathetic nervous system, type 2 diabetes mellitus

\section{Introduction}

Diabetic retinopathy (DR), a potentially devastating complication of diabetes mellitus, is a chronic progressive disease of the retinal microvasculature associated with prolonged hyperglycaemia and other diabetes-related conditions such as hypertension and dyslipidaemia. ${ }^{1}$ Early detection and treatment minimises diabetesrelated visual impairment. ${ }^{2,3}$

Although microvascular occlusion and leakage are recognised as the main pathological processes, ${ }^{3}$ neuroretinal alterations could be present in the absence of clinically detectable retinal vasculopathy. ${ }^{4-8}$ Diabetes-related autonomic 
dysfunction can be easily assessed by studying the dynamics of the pupillary light reflex (PLR).

The PLR is controlled by the autonomic nervous system, which regulates pupil size, primarily in response to light intensity, but also other factors including arousal, drugs, and visual adaptation. ${ }^{9-11}$ After decussation at the optic chiasma, crossed and uncrossed pupillary fibres exit the optic tract and travel to either the olivary pretectal nucleus (OPN) to initiate the parasympathetic PLR, or to the hypothalamus to initiate the sympathetic PLR. Interneurons from each OPN connect to the EdingerWestphal (EW) nuclei on both sides of the brain. The preganglionic neuron travels from the EW nucleus to innervate the ipsilateral ciliary ganglion. The last (postganglionic) neuron connects the ciliary ganglion to the sphincter pupillae of the iris. ${ }^{12}$ From the hypothalamus, the central neuron travels down through the brainstem on each side to synapse in the region of the stellate ganglion. The preganglionic neuron travels upward from the stellate ganglion to synapse at the superior cervical ganglion. The postganglionic neuron ascends into the head and enters the orbit to innervate the dilator pupillae of the iris. $^{12}$

Pupillary abnormalities may precede clinical signs ${ }^{5}$ of diabetic retinopathy and are detectable by examining pupillomotor function. ${ }^{13}$ In diabetes, impairment in sympathetic and/or parasympathetic arms of the PLR have been observed. ${ }^{14-21}$

Since the development of dynamic pupillometry ${ }^{22,23}$, recent advances have enabled objective and repeatable assessments of pupillary function, including dynamic responses such as latency, constriction speed, and redilation speed. However, while studies examining pupillometry measures have included some participants with diabetes, ${ }^{13,21,24-28}$ only a few have been carried out on sample populations with different stages of diabetic retinopathy. ${ }^{24-28}$ These studies have either had relatively small sample sizes and/or reported on too few dynamic pupillometry indices. The aim of this pilot study was to measure and compare pupillometry indices in type 2 diabetes (T2DM) patients - with and without diabetic retinopathy - and in healthy, age-matched controls.

\section{Materials and Methods}

This was a hospital-based, pilot, case-control study. The study was conducted at Dunedin Hospital and community locations in Dunedin, as part of the requirements for the fulfilment of a Master of Ophthalmology (MOphth) by the first author. The MOphth has since been awarded to Dr Bista Karki for a thesis entitled: Dynamic pupillometry in a cohort of individuals with type II diabetes mellitus and establishing a relationship between pupillary dysfunction and the severity of diabetic retinopathy. ${ }^{29}$ Preliminary findings from this study were also presented at the 48th Annual Scientific Congress of the Royal Australian and New Zealand College of Ophthalmologists. ${ }^{30}$

Each participant provided written informed consent. The study was approved by the University of Otago Human Ethics Committee (Reference Number: H16/029) and was conducted in accordance with the principles of the Declaration of Helsinki.

\section{Participants and Recruitment}

Study participants were recruited from 27 March 2016 to 30 September 2016. Cases were individuals with T2DM aged 45-80 years enrolled in the Otago Diabetic Eye Monitoring Service (ODEMS), or attending the Dunedin Hospital Eye Department for assessment, treatment or monitoring of diabetic retinopathy. Controls were healthy 45-80 year olds who were diabetes screen negative.

Exclusion criteria were: a history of intraocular surgery; ocular or neurological conditions that could interfere with normal pupillary function; regular use of prescription or recreational drugs that could interfere with normal pupillary function; signs of iris or pupil abnormalities, or a relative afferent pupillary defect on examination.

The medical notes of potential cases were examined to assess study eligibility prior to their ODEMS or Eye Department appointment. Those who were potentially eligible were invited to participate in the study prior to their appointment. Twenty-two potential participants were excluded for the following reasons: T1DM $(n=5)$; history of intraocular surgery $(\mathrm{n}=7)$; central retinal vein occlusion $(\mathrm{n}=2)$; branch retinal vein occlusion $(\mathrm{n}=3)$; non-arteritic anterior ischaemic optic neuropathy $(\mathrm{n}=1)$; uveitis $(\mathrm{n}=1)$; glaucoma $(\mathrm{n}=1)$; and prescribed medications that could interfere with normal pupillary functioning $(\mathrm{n}=2)$.

Control participants were recruited by advertising at public locations around Dunedin Hospital, and at the central city public library, a Pacific Island church, and optometry practices in Dunedin. An email advertisement was circulated to both Dunedin Hospital and the University of Otago employees. Potential control participants were invited to attend either the Dunedin Hospital Eye Department, or a preferred location (work place, church or home) to assess their study eligibility. They were 
screened for diabetes by undertaking a random capillary blood glucose test using the Care Sens N blood glucose monitoring meter (Pharmaco NZ Ltd, Auckland, New Zealand), by the same clinician who collected the study data. Those with a glucometer reading of greater than 11.1 $\mathrm{mmol} / \mathrm{l}(\mathrm{n}=4)$ were advised to see their general practitioner for further assessment and were excluded from the study.

\section{Data}

Demographic data including date of birth, sex and ethnicity, as well as PLR measurements were collected for all participants. For cases, additional data including duration of diabetes, most recent glycated haemoglobin (HbAlc) test, results of their retinal screen or diabetic retinopathy assessment and the presence or absence of diabetic macular oedema (DME), as defined in the International Clinical Diabetic Macular Edema Disease Severity Scale ${ }^{31}$ were collected from their Eye Department medical records. If DME had been previously diagnosed, this diagnosis was confirmed by an ophthalmologist at their clinical appointment.

\section{Pupillary Light Reflex Measurements}

The constriction and dilation phases of the PLR were measured using the PLR-2000 Dynamic Pupillometer (NeurOptics, Irvine, California, USA). All measurements were made by the same experienced clinician at the same location, with the same controlled ambient lighting, and at the same time period of the day (between 10 am and $2 \mathrm{pm}$ ). Participants' left and right eyes were assessed separately with the participant seated upright. To create similar prestimulus visual environments for both eyes, participants were asked to cover the eye that was not being tested, with their ipsilateral hand for one minute. They were shown how to do this properly by the clinician collecting the data. The PLR-2000 cup was placed over the eye to be tested the same one-minute-long dark adaptation period prior to testing to reduce the effect of ambient room lighting, which was between 200 and 300 lux. The pupillary hippus that was noted in some participants' eyes was reduced when both the non-tested eye and the tested eye were completely covered with the participant's hand and the PLR-2000 cup, respectively. After assessing the initial pupil size under infrared illumination $(949 \mathrm{~nm})$, the pupillometer tracked the response of the pupil during five seconds of continuous recording following the application of a white light stimulus with an intensity of 180 microwatts and a duration of 154
Table I Definitions of the Seven Pupillometry Measures

\begin{tabular}{|c|c|}
\hline Pupillometer Measure & Definition \\
\hline \multicolumn{2}{|c|}{ Parasympathetic pupillary function } \\
\hline Basal pupil diameter (BPD) & Pupillary diameter at a resting phase \\
\hline End pupil diameter (EPD) & $\begin{array}{l}\text { Smallest pupil diameter recorded in } \\
\text { response to the light stimulus }\end{array}$ \\
\hline Latency of pupil & Time lapse before the pupil actually \\
\hline constriction (Reaction & begins to constrict in response to the \\
\hline Time) & light stimulus \\
\hline Maximum constriction & The maximum rate at which the pupil \\
\hline velocity $(\mathrm{MCV})$ & constricts in response to the light stimulus \\
\hline $\begin{array}{l}\text { Average constriction } \\
\text { velocity }(\mathrm{ACV})\end{array}$ & $\begin{array}{l}\text { The average rate at which the pupil } \\
\text { constricts in response to the light stimulus }\end{array}$ \\
\hline \multicolumn{2}{|c|}{ Sympathetic pupillary function } \\
\hline $\begin{array}{l}\text { Average dilation velocity } \\
\text { (ADV) }\end{array}$ & $\begin{array}{l}\text { The average rate at which the pupil } \\
\text { dilates after maximum constriction in } \\
\text { response to the light stimulus }\end{array}$ \\
\hline Recovery time (T75) & $\begin{array}{l}\text { Time for the pupil to dilate to } 75 \% \text { of } \\
\text { the initial, pre-stimulus, steady-state } \\
\text { level (ie } 75 \% \text { of BPD) }\end{array}$ \\
\hline
\end{tabular}

milliseconds. The pupillometer provided a digital output of seven measures (Table 1).

\section{Outcome Measures}

The outcome measures were the basal pupil diameter (BPD), indices of parasympathetic pupillary function (the latency of pupil constriction - reaction time; maximum constriction velocity - MCV; average constriction velocity - ACV; absolute constriction amplitude - ACA, calculated by BPD minus end pupil diameter; relative reflex amplitude - RRA, calculated by $($ ACA/BPD) $\times 100)$, and indices of sympathetic pupillary function (average dilation velocity $-\mathrm{ADV}$; and the $75 \%$ recovery time $-\mathrm{T} 75$ ).

\section{Statistical Analyses}

PLR measurements for both eyes were analysed, but as results were similar those for the right eye only are presented. Cases were categorised according to presence or absence, and severity, of DR - no diabetic retinopathy (no DR), mild or moderate non-proliferative diabetic retinopathy (mild/ moderate NPDR), and severe non-proliferative diabetic retinopathy or proliferative diabetic retinopathy (severe NPDR/ PDR). Normality in the distribution of the data was tested using D'Agostino-Pearson normality test. The means of the outcome measures were compared between the study groups using the Kruskal-Wallis non-parametric test with Dunn's 
multiple comparisons post-test. Multiple linear regression was used to examine the relationship between RRA, MCV, ADV and T75 with HbA1c (as the independent variable). Statistical analyses were carried out with Graphpad InStat 3 (Graphpad Software Inc., San Diego California USA, www. graphpad.com) and Microsoft Excel. The two-sided level of statistical significance was set at $\mathrm{p}<0.05$.

\section{Results}

Two hundred and eighty-one participants (211 cases and 70 controls) were recruited. Of the 211 with T2DM, 56 had no DR, 106 had mild/moderate NPDR, and 49 had severe NPDR/PDR. The demographic characteristics of all participants, and the $\mathrm{HbAlc}$ results for participants with T2DM are detailed in Table 2. There was no difference in mean age across the four groups $(p>0.05)$. There was a higher proportion of females in the control group than the three diabetes groups and New Zealand European was the most common ethnic group. A recent $\mathrm{HbA} 1 \mathrm{c}$ test result was available for $202(95.7 \%)$ cases. Mean HbA1c for the severe NPDR/PDR group was significantly greater than that for each of the other two diabetes groups $(\mathrm{p}<0.01)$.

\section{Dynamic Pupillometry Indices}

The pupillometry measures for each of the four groups are shown in Table 3. With a few exceptions, the PLR indices were significantly altered in participants with diabetes, worsening as diabetic retinopathy progressed. The pupillary constriction indices (ACA, RRA, MCV and ACV) were more markedly affected by diabetes and diabetic retinopathy. Those with diabetes but no diabetic retinopathy had PLR indices that were significantly altered compared to the control group, but not compared to the groups with mild/moderate diabetic retinopathy. The results were not different when analysed by sex. The results are also shown for non-parametric (Kruskal-Wallis Test, with Dunn's Post test) multiple comparisons (one for each PLR index) in Supplementary Table S1.

\section{Diabetic Macular Edema (DME)}

Forty-five cases had DME, which included 18 of 106 $(17.0 \%)$ with mild/moderate NPDR and 27 of 49 $(55.1 \%)$ with severe NPDR/PDR (Table 3). In the subgroup with severe NPDR/PDR, there were no significant differences $(\mathrm{p}=0.550)$ in RRA in those with $(28 \% \pm 9$ (95\% CI; 24, 31)), and without DME (26\% \pm 9 (95\% CI; $22,30))$. Similarly, there was no significant difference $(\mathrm{p}=$ $0.305)$ in the mean ADV between those with DME $(0.94 \mathrm{~mm} / \mathrm{s} \pm 0.36(95 \% \mathrm{CI} ; 0.79,1.1))$ and those without DME $(0.83 \mathrm{~mm} / \mathrm{s} \pm 0.32$ (95\% CI; 0.69, 0.97)).

There were no statistically significant correlations between HbA1c and the pupillometry indices; RRA ( $\mathrm{r}=$

Table 2 Demographic Characteristics of the Control and Diabetes Groups, and HbAlc Profile of the Diabetes Population by Retinopathy Group

\begin{tabular}{|c|c|c|c|c|c|}
\hline & Controls & No DR & Mild/Moderate NPDR & Severe NPDR/PDR & Total \\
\hline $\mathrm{n}$ & 70 & 56 & 106 & 49 & 281 \\
\hline \multicolumn{6}{|l|}{ Age (years) } \\
\hline Mean \pm SD & $60 \pm 9$ & $63 \pm 10$ & $63 \pm 10$ & $63 \pm 11$ & $62 \pm 14$ \\
\hline \multicolumn{6}{|l|}{ Sex } \\
\hline Male, n (\%) & $19(27.1)$ & $30(53.6)$ & $56(52.8)$ & $23(46.9)$ & $128(45.6)$ \\
\hline Female, n (\%) & 51 (73.9) & $26(46.4)$ & $50(47.2)$ & $26(53.1)$ & $153(54.4)$ \\
\hline \multicolumn{6}{|l|}{ Ethnicity } \\
\hline NZ European, n (\%) & $57(81.4)$ & $50(89.3)$ & $90(84.9)$ & $37(75.5)$ & $234(83.3)$ \\
\hline Māori, n (\%) & 0 & $2(3.6)$ & $5(4.7)$ & $3(6.1)$ & $10(3.6)$ \\
\hline Asian, $\mathrm{n}(\%)$ & $5(7.1)$ & $3(5.4)$ & $6(5.7)$ & $5(10.2)$ & $19(6.8)$ \\
\hline Pacific, n (\%) & $8(11.4)$ & $\mathrm{I}(\mathrm{I} .8)$ & $5(4.7)$ & $4(8.2)$ & $18(6.4)$ \\
\hline \multicolumn{6}{|l|}{$\mathrm{HbAlc}(\mathrm{mmol} / \mathrm{mol})$} \\
\hline Recent test, n (\%) & - & $55(98.2)$ & $99(93.4)$ & $48(98.0)$ & $202(96.2)$ \\
\hline Mean \pm SD & - & $55 \pm 13$ & $58 \pm 17$ & $64 \pm 14$ & \\
\hline Range & - & $37-98$ & $20-114$ & $37-99$ & \\
\hline
\end{tabular}

Abbreviations: DR, diabetic retinopathy; $n$, number of participants; NPDR, non-proliferative diabetic retinopathy; NZ, New Zealand; PDR, proliferative diabetic retinopathy; SD, standard deviation. 
Table 3 Summary of the Pupillometry Indices Measured for Each of the Four Study Groups. Each of the Three Diabetes Was Compared with the Control Group Using Dunn's Multiple Comparison Test

\begin{tabular}{|c|c|c|c|c|c|c|c|}
\hline & Control & \multicolumn{2}{|l|}{ No DR } & \multicolumn{2}{|c|}{ Mild/Moderate NPDR } & \multicolumn{2}{|c|}{ Severe NPDR/PDR } \\
\hline $\mathrm{n}$ & 70 & 56 & & 106 & & 49 & \\
\hline DME, n (\%) & 0 & 0 & & $18(17.0)$ & & $27(55.1)$ & \\
\hline $\begin{array}{l}\text { Pupillometry indices } \\
\text { BPD }(\mathrm{mm})\end{array}$ & $\begin{array}{l}\text { Mean } \pm \text { SD } \\
4.9 \pm 0.8\end{array}$ & $\begin{array}{l}\text { Mean } \pm \text { SD } \\
4.5 \pm 0.8\end{array}$ & $\begin{array}{l}p \text { value } \\
<0.05\end{array}$ & $\begin{array}{l}\text { Mean } \pm \text { SD } \\
4.5 \pm 0.8\end{array}$ & $\begin{array}{l}p \text { value } \\
<0.01\end{array}$ & $\begin{array}{l}\text { Mean } \pm \text { SD } \\
3.8 \pm 0.7\end{array}$ & $\begin{array}{l}p \text { value } \\
<0.001\end{array}$ \\
\hline $\begin{array}{l}\text { Parasympathetic } \\
\text { Reaction time - latency }(\mathrm{s}) \\
\text { MCV }(\mathrm{mm} / \mathrm{s}) \\
\text { ACV }(\mathrm{mm} / \mathrm{s}) \\
\text { ACA }(\mathrm{mm}) \\
\text { RRA }(\%)\end{array}$ & $\begin{array}{l}0.2 \pm 0.03 \\
4.9 \pm 0.9 \\
3.7 \pm 0.6 \\
1.7 \pm 0.3 \\
35 \pm 5.4\end{array}$ & $\begin{array}{l}0.2 \pm 0.04 \\
4.0 \pm 0.8 \\
3.0 \pm 0.7 \\
1.4 \pm 0.3 \\
31 \pm 5.7\end{array}$ & $\begin{array}{l}>0.05 \\
<0.001 \\
<0.001 \\
<0.001 \\
<0.001\end{array}$ & $\begin{array}{l}0.2 \pm 0.03 \\
4.2 \pm 0.9 \\
3.2 \pm 0.7 \\
1.5 \pm 0.3 \\
33 \pm 5.7\end{array}$ & $\begin{array}{l}<0.01 \\
<0.001 \\
<0.001 \\
<0.001 \\
<0.05\end{array}$ & $\begin{array}{l}0.3 \pm 0.05 \\
3.4 \pm 1.0 \\
2.4 \pm 1.0 \\
1.0 \pm 0.4 \\
27 \pm 8.7\end{array}$ & $\begin{array}{l}<0.001 \\
<0.001 \\
<0.001 \\
<0.001 \\
<0.001\end{array}$ \\
\hline $\begin{array}{l}\text { Sympathetic } \\
\qquad \text { ADV (mm/s) } \\
\text { T75 (s) }\end{array}$ & $\begin{array}{l}1.2 \pm 0.2 \\
2.0 \pm 0.7\end{array}$ & $\begin{array}{l}1.0 \pm 0.3 \\
2.0 \pm 0.8\end{array}$ & $\begin{array}{l}<0.001 \\
>0.05\end{array}$ & $\begin{array}{l}\mathrm{I} . \mathrm{I} \pm 0.2 \\
\mathrm{I} .9 \pm 0.7\end{array}$ & $\begin{array}{l}<0.05 \\
>0.05\end{array}$ & $\begin{array}{l}0.9 \pm 0.3 \\
1.6 \pm 0.7\end{array}$ & $\begin{array}{l}<0.001 \\
<0.01\end{array}$ \\
\hline
\end{tabular}

Abbreviations: ACA, absolute constriction amplitude; ACV, average constriction velocity; ADV, average dilation velocity; BPD, basal pupil diameter; DME, diabetic macular oedema; DR, diabetic retinopathy; MCV, maximum constriction velocity; mm, millimetres; NPDR, non-proliferative diabetic retinopathy; PDR, proliferative diabetic retinopathy; RRA, relative reflex amplitude; s, seconds; T75, 75\% recovery time.

0.006, $\mathrm{p}=0.93), \operatorname{MCV}(\mathrm{r}=0.085, \mathrm{p}=0.229), \operatorname{ADV}(\mathrm{r}=$ $0.020, \mathrm{p}=0.825)$, and T75 $(\mathrm{r}=0.022, \mathrm{p}=0.758)$.

\section{Discussion}

To our knowledge, this is the third study to demonstrate measurable differences in PLR in diabetic patients compared with an age-matched control group. The findings from this study are consistent with those of Jain et $\mathrm{al}^{27}$ and Kiziltoprak et $\mathrm{al}^{28}$ both of which also described abnormalities in the PLR in the early stages of retinopathy that worsened with progression. While a larger study is required, the findings from this pilot study indicate the potential clinical utility of screening for changes in PLR as part of routine diabetes care. This is especially because, unlike in the previous two studies, diabetic autonomic neuropathy in this study preceded clinically observable signs of diabetic retinopathy. In this study, of the five parasympathetic PLR indices, only RRA and latency showed relatively ambiguous results. Whereas for ACA, $\mathrm{MCV}$ and $\mathrm{ACV}$, all comparisons were significantly different, except for those between the no DR and the mild/ moderate NPDR groups. This suggests that neuropathy precedes clinical signs of diabetic retinopathy. How much of this neuropathy is autonomic, how much is due to retinopathy, and how much is due to retinal ganglion cell damage is still to be determined. Prior treatment with pan-retinal photocoagulation among those with severe
NPDR/PDR also needs to be considered. The results for the sympathetic PLR indices - ADV and T75 - were not as consistent. For diabetes cases, the BPD was significantly smaller than that for the control group, and the severe NPDR/PDR group had an appreciably smaller BPD (3.8 $\mathrm{mm})$ compared with the other two retinopathy groups $(4.5 \mathrm{~mm})$ and the control group $(4.9 \mathrm{~mm})$.

Compared with the control group the ACA measure was significantly smaller in each of the diabetes groups. This observation is supported by Yuan et $\mathrm{al}^{21}$ who reported that ACA is not significantly affected in other (non-diabetic) forms of autonomic neuropathy, whereas it is significantly affected in diabetic autonomic neuropathy (DAN). This suggests that there might be selective involvement of the pupils in DAN. Since ACA is dependent on initial pupil size, a more independent measurement of ACA is RRA, the total constriction as a percentage of initial pupil size. Muppidi et $\mathrm{al}^{13}$ found that the reflex constriction amplitude (equivalent to RRA in our study) was significantly reduced in individuals with moderate to severe autonomic failure (diabetic and non-diabetic) compared to healthy controls, which is consistent with our Dunedin study.

The MCV results from our study are similar to those of Ketner et $\mathrm{al}^{32}$ and Yuan et al, ${ }^{21}$ but inconsistent with those of Levy et al. ${ }^{14}$ Yuan et $\mathrm{al}^{21}$ also demonstrated that the parasympathetic pupillary indices (MCV and ACA) 
correlated well with cardiac parasympathetic failure in diabetes, but not with sympathetic pupillary indices. They also observed that the abnormal slowing of MCV occurred in twice the number of patients with DAN as compared with non-DAN. Our results suggest that latency is unaffected until DR is present, with no significant differences between the control versus no DR, and no DR versus mild/moderate groups.

While our results for ADV and T75 are similar to other published results, there were some differences. Ketner et $\mathrm{al}^{32}$ only found a significant difference in ADV between the no DR and the PDR groups, whereas, in our study, only the comparison between the mild/moderate NPDR and severe NPDR/PDR groups was statistically significant. Yuan et $\mathrm{al}^{21}$ found that $\mathrm{T} 75$ was significantly delayed in participants with either diabetic or non-diabetic autonomic neuropathy compared to healthy controls. Our results suggest that the delay becomes significant when DR is at the severe NPDR to PDR stage.

Of the 211 cases in this study, almost three-quarters (73\%) had some form of diabetic retinopathy. This proportion is substantially higher than findings from other diabetic retinopathy prevalence studies in New Zealand, in which $20-25 \%$ of diabetes patients had some form of DR. ${ }^{33-36}$ This large difference may be explained by the fact that this Dunedin study was hospital-based, whereas the others were region-wide community population-based studies. ${ }^{33-36}$

Diabetic macular oedema (DME) is the underlying cause for the majority of vision loss associated with diabetes, ${ }^{37}$ and it can present at any stage of DR. In our study, $20 \%$ of those with diabetes had DME, and they all had DR. A greater proportion (55\%) of participants with severe NPDR/PDR also had DME compared with $17 \%$ of those with mild/moderate NPDR. While the proportion with DME increased with increasing severity of DR, this did not have any effect on the PLR. However, only a small number of participants had DME, increasing the likelihood of a type II statistical error.

No published studies have specifically examined the effect of macular oedema on the PLR, even though some clinicians believe that macular oedema may have an indirect effect on the PLR. The problem with teasing out this effect is twofold. First, DME can occur at any stage of DR. As pupillometry results, which depend on the stage of the DR, are more difficult to read in the presence of macula oedema, interpreting whether any poor results are due to the macula oedema or DR severity is also difficult. Second, the diminished PLR observed with DR is a neuropathy, which progresses via a pathway that is, at least in part, separate from the progression of microvasculopathy on the retina in general, and within the macula area in particular.

In our study, the most recent $\mathrm{HbAlc}$ results (measured within 3 months of enrolment into the study) were available for 202 of 211 (95.7\%) participants, and mean HbA1c increased with increasing severity of retinopathy. While there are other risk factors for DR, poor glycemic control is the most important risk factor for the progression of DR. ${ }^{38,39}$ This was evident in our study with the highest mean $\mathrm{HbAlc}(64 \pm 14 \mathrm{mmol} / \mathrm{mol})$ in the group with severe proliferative retinal changes and lowest, but still elevated $(55 \pm 13 \mathrm{mmol} / \mathrm{mol})$ in the group with no signs of DR. There was no statistically significant correlation between $\mathrm{HbAlc}$ and any of the parasympathetic (RRA and MCV) and sympathetic (ADV and T75) indices. In contrast to our findings, Donaghue et $\mathrm{al}^{16}$ found a significant inverse correlation between a change in $\mathrm{HbAlc}$ over 1.5 years and a change in BPD and MCV (but not with RRA) in adolescents with type 1 diabetes. Although the Donaghue et al ${ }^{16}$ study examined people with type 1 diabetes, and we included only those with T2DM, the most likely explanation for the difference in these results is study design with our study being cross-sectional and the Donaghue et $\mathrm{al}^{16}$ study being longitudinal. Kiziltoprak et $\mathrm{al}^{28}$ also found an inverse relationship between $\mathrm{HbA} 1 \mathrm{c}$ levels and pupillary measurements, and their study, like ours, was crosssectional with the only difference being that they assessed the $\mathrm{HbAlc}$ levels at the same time as the study was carried out, as opposed to our study in which we relied on the most recent $\mathrm{HbAlc}$ results and we did not have any data for nine participants with diabetes. It is possible that these differences may have had an impact on the discrepancy between our results and theirs.

The main strength of our pilot study is that, for only the third time, we have compared the PLR across groups of participants with T2DM and different stages of diabetic retinopathy, with an age-matched control group. As this was a pilot study, and the overall sample size was relatively small, the number of participants in each retinopathy sub-group, and with macular edema was small. As such, we were unable to assess whether there are likely to be differences between ethnic groups, and between those with and without prior pan-retinal photocoagulation. Similarly, missing medical history information limited comparisons between groups. A full multi-center study would seek to confirm our observations, and examine whether there are differences between the main ethnic 
groups in New Zealand (indigenous Maori, Pacific and Asian). The cross-sectional design of our study is also a limitation, although it is unlikely that reverse-causality is an issue.

In conclusion, our results suggest that the PLR is significantly impaired with diabetic retinal neuropathy, before there are clinically observable signs of diabetic retinopathy. Signs of parasympathetic dysfunction in diabetic patients are measurable when there are no clinically observable signs of diabetic retinopathy, whereas signs of sympathetic dysfunction become obvious only when the (non-proliferative) diabetic retinopathy is moderate to severe. Dynamic pupillometry may be a cheap, clinically relevant test, but sensitivity and specificity need to be determined before utilizing it as a screening tool for diabetic retinopathy.

\section{Compliance with Ethical Standards}

Disclosure of potential conflicts of interest: None reported

Research involving human. Ethical approval: All procedures performed in studies involving human participants were in accordance with the ethical standards of the University of Otago Human Ethics Committee (Reference Number: H16/029) and with the 1964 Helsinki declaration and its later amendments or comparable ethical standards.

Informed consent: Informed written consent was obtained from all individual participants included in the study.

\section{Acknowledgments}

Samyukta Bista Karki was awarded a Molteno Scholarship through the Ophthalmology Society of New Zealand (OSNZ) Post Graduate Education Trust, Dunedin, New Zealand.

\section{Disclosure}

Samyukta Bista Karki reports a grant from the Ophthalmology Society of New Zealand (OSNZ) Post Graduate Education Trust (PET). The authors report no other potential conflicts of interest for this work.

\section{References}

1. Smith SE, Smith SA, Brown PM, Fox C, Sönksen PH. Pupillary signs in diabetic autonomic neuropathy. $\mathrm{Br}$ Med J. 1978;2:924-927. doi:10.1136/bmj.2.6142.924

2. The Early Treatment Diabetic Retinopathy Study Research Group. Photocoagulation for diabetic macular edema: early treatment diabetic retinopathy study report number 1. Arch Ophthalmol. 1985;103:1796-1806. doi:10.1001/archopht.1985.01050120030015

3. Yanoff M, Duker SJ. Diabetes Mellitus. In: Yanoff M, Sassani JW, editors. Ocular Pathology. 4th ed. London: Elsevier Health Sciences; 2013:527-553.
4. Eisma JH, Dulle JE, Fort PE. Current knowledge on diabetic retinopathy from human donor tissues. World J Diabetes. 2015;6:312-320. doi:10.4239/wjd.v6.i2.312

5. van Dijk HW, Verbraak FD, Stehouwer M, et al. Association of visual function and ganglion cell layer thickness in patients with diabetes mellitus type 1 and no or minimal diabetic retinopathy. Vision Res. 2011;51:224-228. doi:10.1016/j.visres.2010.08.024

6. van Dijk HW, Verbraak FD, Kok PH, et al. Early neurodegeneration in the retina of type 2 diabetic patients. Invest Ophthalmol Vis Sci. 2012;53:2715-2719. doi:10.1167/iovs.11-8997

7. van Dijk HW, Kok PH, Garvin M, et al. Selective loss of inner retinal layer thickness in type 1 diabetic patients with minimal diabetic retinopathy. Invest Ophthalmol Vis Sci. 2009;50:3404-3409. doi:10. 1167/iovs.08-3143

8. Demirkaya N, van Dijk HW, van Schuppen SM, et al. Effect of age on individual retinal layer thickness in normal eyes as measured with spectral-domain optical coherence tomography. Invest Ophthalmol Vis Sci. 2013;54:4934-4940. doi:10.1167/iovs.13-11913

9. Loewenfeld IE, Lowenstein O. The Pupil: Anatomy, Physiology, and Clinical Applications. Iowa: Iowa State University Press; 1993.

10. Gamlin PD, McDougal DH, Pokorny J, Smith VC, Yau KW, Dacey DM. Human and macaque pupil responses driven by melanopsin-containing retinal ganglion cells. Vision Res. 2007;47:946-954. doi:10.1016/j.visres.2006.12.015

11. Kardon RH. Regulation of light through the pupil. In: Levin LA, Nilsson SFV, Ver Hoeve J, Wu S, Kaufman PL, Alm A, editors. Adler's Physiology of the Eye. New York: Elsevier Health Sciences; 2011:502-525.

12. Levin LA, Nilsson SFV, Ver Hoeve J, Wu S, Kaufman PL, Alm A. Adler's Physiology of the Eye. New York: Elsevier Health Sciences; 2011.

13. Muppidi S, Adams-Huet B, Tajzoy E, et al. Dynamic pupillometry as an autonomic testing tool. Clin Auton Res. 2013;23:297-303. doi:10.1007/s10286-013-0209-7

14. Levy DM, Rowley DA, Abraham RR. Portable infrared pupillometry using Pupilscan: relation to somatic and autonomic nerve function in diabetes mellitus. Clin Auton Res. 1992;2:335-341. doi:10.1007/ BF01824304

15. Karavanaki K, Davies AG, Hunt LP, Morgan MH, Baum JD. Pupil size in diabetes. Arch Dis Child. 1994;71:511-515. doi:10.1136/ adc.71.6.511

16. Donaghue KC, Pena MM, Fung AT, et al. The prospective assessment of autonomic nerve function by pupillometry in adolescents with type 1 diabetes mellitus. Diabet Med. 1995;12:868-873. doi:10.1111/ j.1464-5491.1995.tb00388.x

17. Koc F, Kansu T, Kavuncu S, Firat E. Topical apraclonidine testing discloses pupillary sympathetic denervation in diabetic patients. J Neuroophthalmol. 2006;26:25-29. doi:10.1097/01.wno.0000204648. 79744.71

18. Crosson CK, Heath AR, Devries GW, Potter DE. Pharmacological evidence for heterogeneity of ocular alpha 2 adrenoceptors. Curr Eye Res. 1992;11:963-970. doi:10.3109/02713689209033494

19. Yang Y, Yu Y, Yao K. Pupillary dysfunction in type 2 diabetes mellitus to refine the early diagnosis of diabetic autonomic neuropathy. NeuroOphthalmology. 2006;30:17-21. doi:10.1080/01658100600599527

20. Cahill M, Eustace P, de Jesus V. Pupillary autonomic denervation with increasing duration of diabetes mellitus. $\mathrm{Br} J$ Ophthalmol. 2001;85:1225-1230. doi:10.1136/bjo.85.10.1225

21. Yuan D, Spaeth EB, Vernino S, Muppidi S. Disproportionate pupillary involvement in diabetic autonomic neuropathy. Clin Auton Res. 2014;24:305-309. doi:10.1007/s10286-014-0258-6

22. Smith SA, Dewhirst RR. A simple diagnostic test for pupillary abnormality in diabetic autonomic neuropathy. Diabet Med. 1986;3:38-41. doi:10.1111/j.1464-5491.1986.tb00703.x

23. Neil HAW, Smith S. A simple clinical test of pupillary autonomic function: correlation with cardiac autonomic function tests in diabetes. Neuro-Ophthalmology. 1989;9:237-242. 
24. Clark CV. Ocular autonomic nerve function in proliferative diabetic retinopathy. Eye. 1988;2(1):96-101. doi:10.1038/eye.1988.20

25. Datta S, Biswas NR, Saxena R, et al. Ocular and cardiovascular autonomic function in diabetic patients with varying severity of retinopathy. Indian J Physiol Pharmacol. 2005;49(2):171-178.

26. Park JC, Chen YF, Blair NP, et al. Pupillary responses in non-proliferative diabetic retinopathy. Sci Rep. 2017;7:44987. doi:10.1038/srep44987

27. Jain M, Devan S, Jaisankar D, Swaminathan G, Pardhan S, Raman R. Pupillary abnormalities with varying severity of diabetic retinopathy. Sci Rep. 2018;8(1):5636. doi:10.1038/s41598-018-24015-9

28. Kiziltoprak H, Tekin K, Sekeroglu MA, Yetkin E, Doguizi S, Yilmabas P. Static and dynamic pupillary responses in patients with different stages of diabetic retinopathy. Neuro-Ophthalmology. 2020;44(4):226-235. doi:10.1080/01658107.2019.1671465

29. Karki SB Dynamic Pupillometry in a Cohort of Individuals with Type II Diabetes Mellitus and Establishing a Relationship Between Pupillary Dysfunction and the Severity of Diabetic Retinopathy (Thesis, Master of Ophthalmology). University of Otago; 2017. Available from: http://hdl.handle.net/10523/7578.

30. Karki S, Mitchell L, Coppell K, Ogbuehi K. Dynamic pupillometry in a cohort of individuals with type II diabetes mellitus and to establish a correlation between pupillary dysfunction and the severity of diabetic retinopathy [Abstract]. Clin Exp Ophthalmol. 2016;44(Suppl. 1):129. doi:10.1111/ceo.12857

31. International Council of Ophthalmology. International clinical diabetic macular edema disease severity scale. California: International Council of Ophthalmology; 2002. Available from: http://www.icoph. org/resources/44/International-Clinical-Diabetic-Macular-EdemaDisease-Severity-Scale-.html.
32. Ketner S, Zhou Z, Yondorf C, Levine J, Banik R. Dynamic Pupillometry in diabetic patients with and without diabetic retinopathy. Invest Ophthalmol Vis Sci. 2012;53:2871.

33. Papali'i-Curtin AT, Dalziel DM. Prevalence of diabetic retinopathy and maculopathy in Northland, New Zealand: 2011-2012. N Z Med J. $2013 ; 126: 20-28$.

34. Frederikson LG, Jacobs RJ. Diabetes eye screening in the Wellington region of New Zealand: characteristics of the enrolled population (2002-2005). N Z Med J. 2008;121:21-34.

35. Chang LY, Lee AC, Sue W. Prevalence of diabetic retinopathy at first presentation to the retinal screening service in the greater Wellington region of New Zealand 2006-2015, and implications for models of retinal screening. $N Z$ Med J. 2017;130:78-88.

36. Coppell KJ, Anderson K, Williams SM, Lamb C, Farmer VL, Mann JI. The quality of diabetes care: a comparison between patients enrolled and not enrolled on a regional diabetes register. Prim Care Diabetes. 2011;5:131-137. doi:10.1016/j.pcd.2010.10.005

37. Klein R, Klein BE, Moss SE, Cruickshanks KJ. The Wisconsin epidemiologic study of diabetic retinopathy. XV. The long-term incidence of macular edema. Ophthalmology. 1995;102:7-16. doi:10.10 16/S0161-6420(95)31052-4

38. Sabanayagam C, Liew G, Tai ES, et al. Relationship between glycated haemoglobin and microvascular complications: is there a natural cut-off point for the diagnosis of diabetes? Diabetologia. 2009;52:1279-1289. doi:10.1007/s00125-009-1360-5

39. Davis MD, Fisher MR, Gangnon RE, et al. Risk factors for high-risk proliferative diabetic retinopathy and severe visual loss: early treatment diabetic retinopathy study report \#18. Invest Ophthalmol Vis Sci. 1998;39:233-252.
Clinical Ophthalmology

\section{Publish your work in this journal}

Clinical Ophthalmology is an international, peer-reviewed journal covering all subspecialties within ophthalmology. Key topics include: Optometry; Visual science; Pharmacology and drug therapy in eye diseases; Basic Sciences; Primary and Secondary eye care; Patient Safety and Quality of Care Improvements. This journal is indexed on PubMed

\section{Dovepress}

Central and CAS, and is the official journal of The Society of Clinical Ophthalmology (SCO). The manuscript management system is completely online and includes a very quick and fair peer-review system, which is all easy to use. Visit http://www.dovepress.com/ testimonials.php to read real quotes from published authors. 